\title{
Bespoke Method for Installation of VIPs on Building Walls and their Performance
}

\author{
Jose Tavares*, Harjit Singh, Maria Kolokotroni \\ Institute of Energy Futures, Brunel University London, United Kingdom \\ Email:jose.tavares@brunel.ac.uk
}

\begin{abstract}
This paper describes the installation method of Vacuum Insulation Panels (VIPs) externally on a demonstration wall in an operational residential building in the UK. The study assesses the effectiveness the VIPs in terms of the heat loss through the walls using temperature profiles measured in the demonstration application. The analysis of the temperature measurements show that VIPs improved the overall insulation capabilities of the wall by $200 \%$. Thermal imaging indicates that the simplified method of application implemented is able to achieve a low thermal bridging effect.
\end{abstract}

KEYWORDS: Retrofit, Vacuum insulation panel (VIP), Thermal performance

\section{INTRODUCTION}

Vacuum Insulated Panels (VIPs) offer an excellent thermal resistance, up to 5-8 times higher than traditional insulation materials. If performing without any loss of vacuum, a $30 \mathrm{~mm}$ thick VIP with a Uvalue of $0.2 \mathrm{~W} /\left(\mathrm{m}^{2} \mathrm{~K}\right)$ is comparable up to a $300 \mathrm{~mm}$ thick commonly used insulation materials, such as glass wool. VIPs help to create a homogeneous temperature distribution through building elements, reduce transmission of water vapour preventing condensation problems and meet minimum fire and sound regulations. The use of super insulation materials such as VIPs is one of the most promising solutions for the construction sector. Even including thermal loss due to the thermal bridge effect, they still perform 5 times better than typical insulation materials [1,2] while keeping the total thickness of the insulation barrier to a minimum which is desirable for retrofit applications. Despite being a very efficient technology, only a small amount, $10 \%$, is used in the building industry and it is well known that the energy use of the EU's building stock accounts for about $40 \%$ of the overall energy use of which households make up about $25 \%$. Additionally, the volume of new buildings per year is currently very low in many developed countries, a trend which seems it will continue in the future [3]. Therefore, retrofitting existing buildings will play an important role in order to meet the targets for decarbonization of buildings as required by EU energy strategy for 2020, 2030 and 2050. Increasing the use of VIPs in the building industry could be an important solution to improve significantly the energy performance of buildings and fulfil the objective of delivering zero-energy buildings. However, there are a number of techno-economic challenges which remain in the way of their widespread adoption: the vulnerability of the VIPs at the stage of installation[4]; the risk of surface condensation; the thermal bridging effect which can affect the panels performance in the long term [5,6]; predicting and ensuring service-life performance and the high initial cost compared to common insulating materials on average 5 times higher. Nonetheless, these have been shown to have a short payback period of 2.5 years in London when the cost of space savings are accounted for [7,8]. Other barriers facing VIPs include the lack of long-term performance data from real case studies as well as the lack of accredited installers. This paper outlines the construction details and challenges regarding the implementation of VIPs, their thermophysical performance and the instrumentation and monitoring regime used for long-term analysis of the thermal performance of a VIP insulated wall system at Brunel University London.

\section{RETROFIT APPROACH AND CASE STUDY BUILDING}

The installation was carried as part of the $\mathrm{ReCO}_{2}$ st project. The $\mathrm{ReCO}{ }_{2} \mathrm{ST}$ Consortium consists of 17 partners from nine countries, 12 industrial partners and four non-profit research organisations with ongoing projects at four residential buildings: Brunel University London; Vevey - Switzerland; Cadiz Spain and Frederikshaven - Denmark [9]. In the demonstration buildings the project aims to provide experimentally validated test results and case studies under real climatic conditions with the aim to increase the confidence of the building sector and homeowners in VIPS. 
Apart from VIPs, the ReCO2ST project provides a range of low $\mathrm{CO}_{2}$ technological and bespoke solutions to different retrofit scenarios: Cool materials; PV arrays; Smart windows; Nature based solutions; Cooling evaporative ventilated façade and Ventilation system with Phase Change Materials.

This paper reports on VIPs which were applied on the ground floor of a student accommodation building (Figs. 1 and 2) onto two walls. The North wall has limited exposure to direct solar radiation throughout the year whereas the South wall has full exposure except early morning when is partially shaded by the adjacent building.

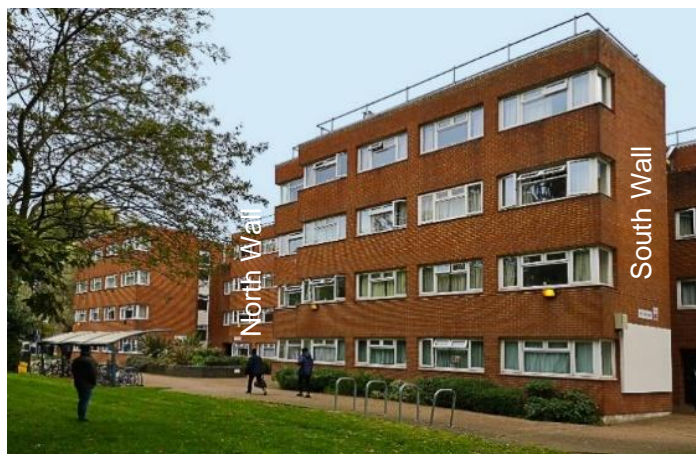

Fig.1 - Façade student accommodation building

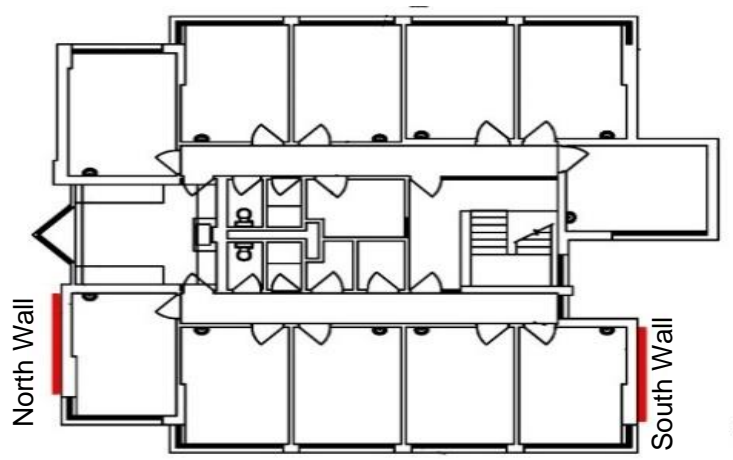

Fig.2 - Plan of the building - Ground Floor

\section{VIP'S PROPERTIES, ASSEMBLING METHOD AND INSTALLATION CHALLENGES}

The installed VIPs were supplied by va-Q-tec AG Germany. The panels, flat in shape of size $1000 \times 600 \times 30 \mathrm{~mm}$ consist of a pressed powder board of fumed silica, non-flammable (class A1) and sealed under vacuum with a gas-vapour-tight film, covered on both sides by a $10 \mathrm{~mm}$ layer of EPS (Fig $3 a$ and $b$ ). The aluminium laminated envelop provides a good barrier for penetrating gases and water vapours. The EPS cover on both sides of the panel not only protects from handling damage but also protects it from surface condensation.
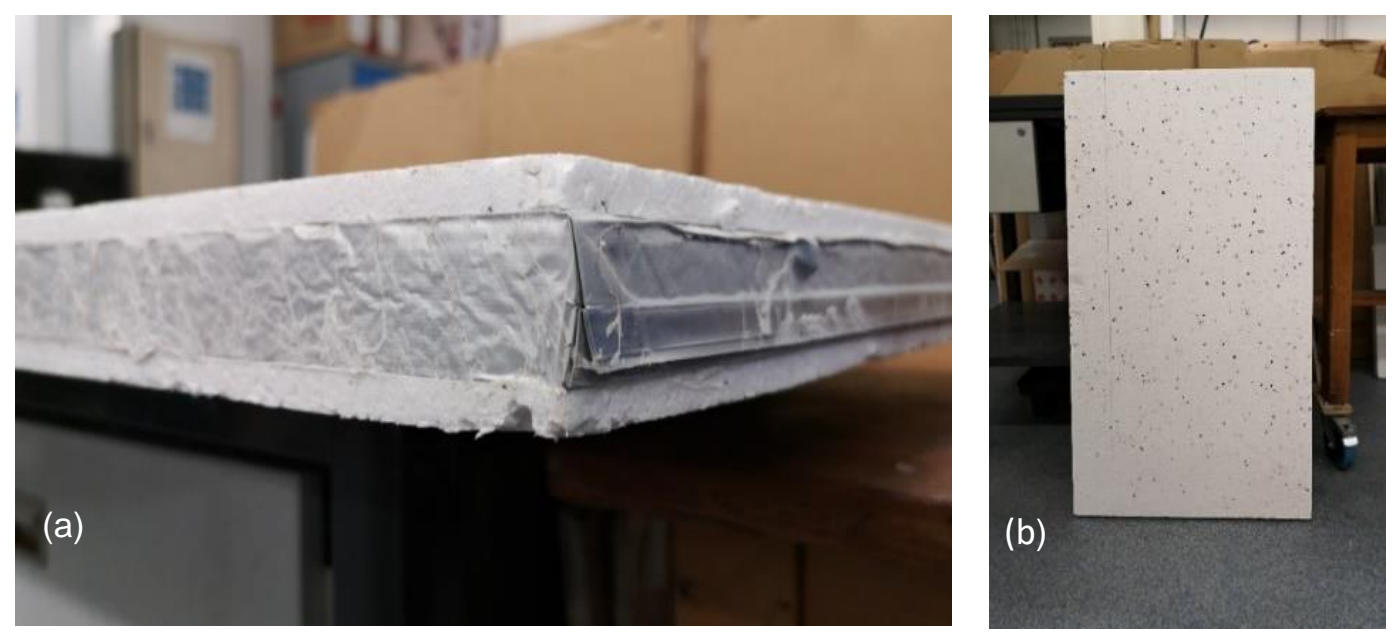

Fig. $3 a$ and $b$-VIP panel with EPS cover on both sides

With a thermal conductivity value of $0.0070 \mathrm{~W} /(\mathrm{mK})$ at $20 \mathrm{~mm}$ thickness, VIPs are predicted to have a service life of up to 60 years by their manufacturer, va-Q-tec. In this project, 9 VIP panels were installed on each wall supported by a wooden frame and covered by a water-proof cement board for external use. The bespoke installation procedure adopted, shown in Fig. 4 and Fig. 5, was developed by the project team after studying conventional methods and deliberations with the manufacturer. 


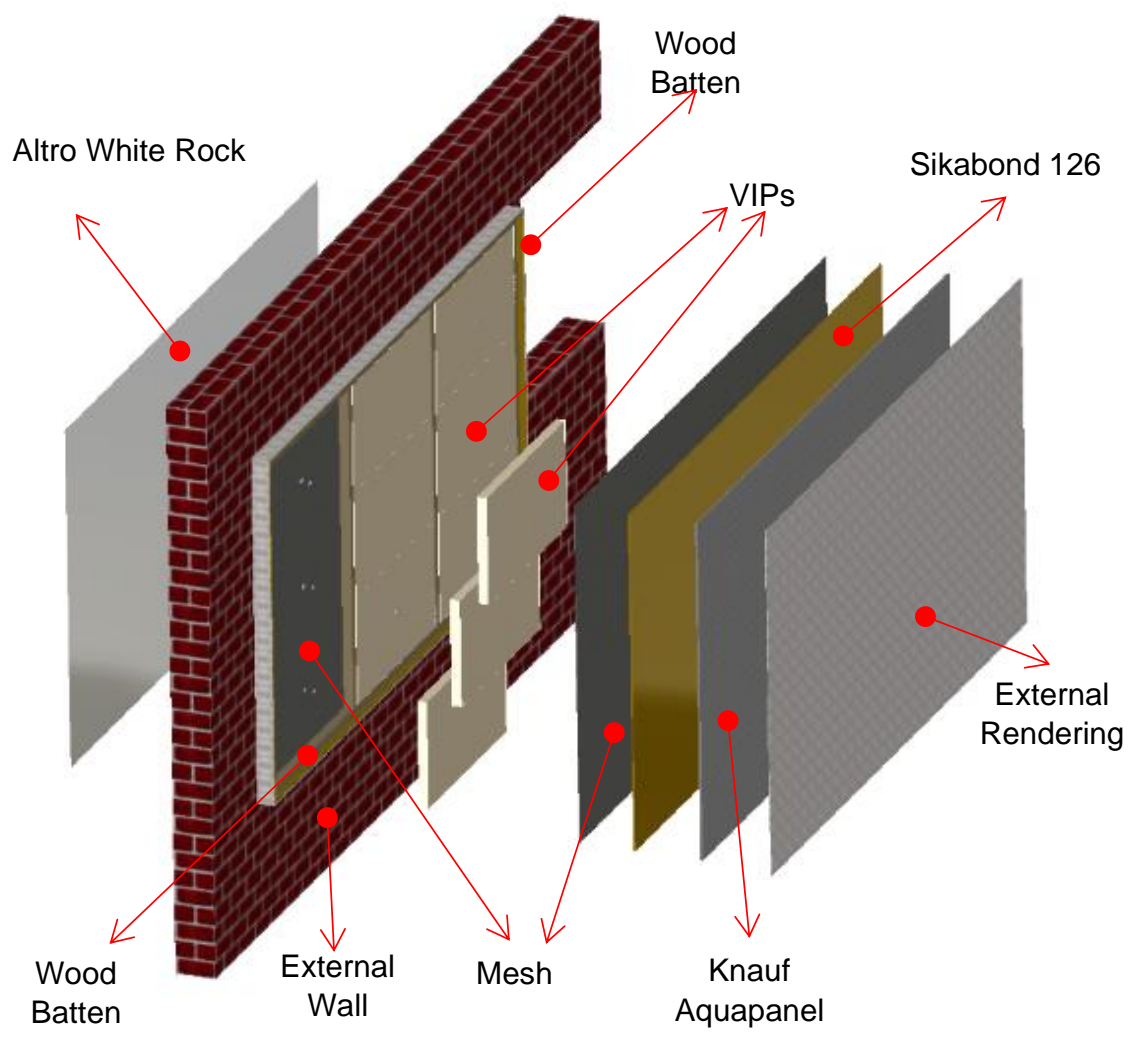

Fig.4 - VIP assembling method
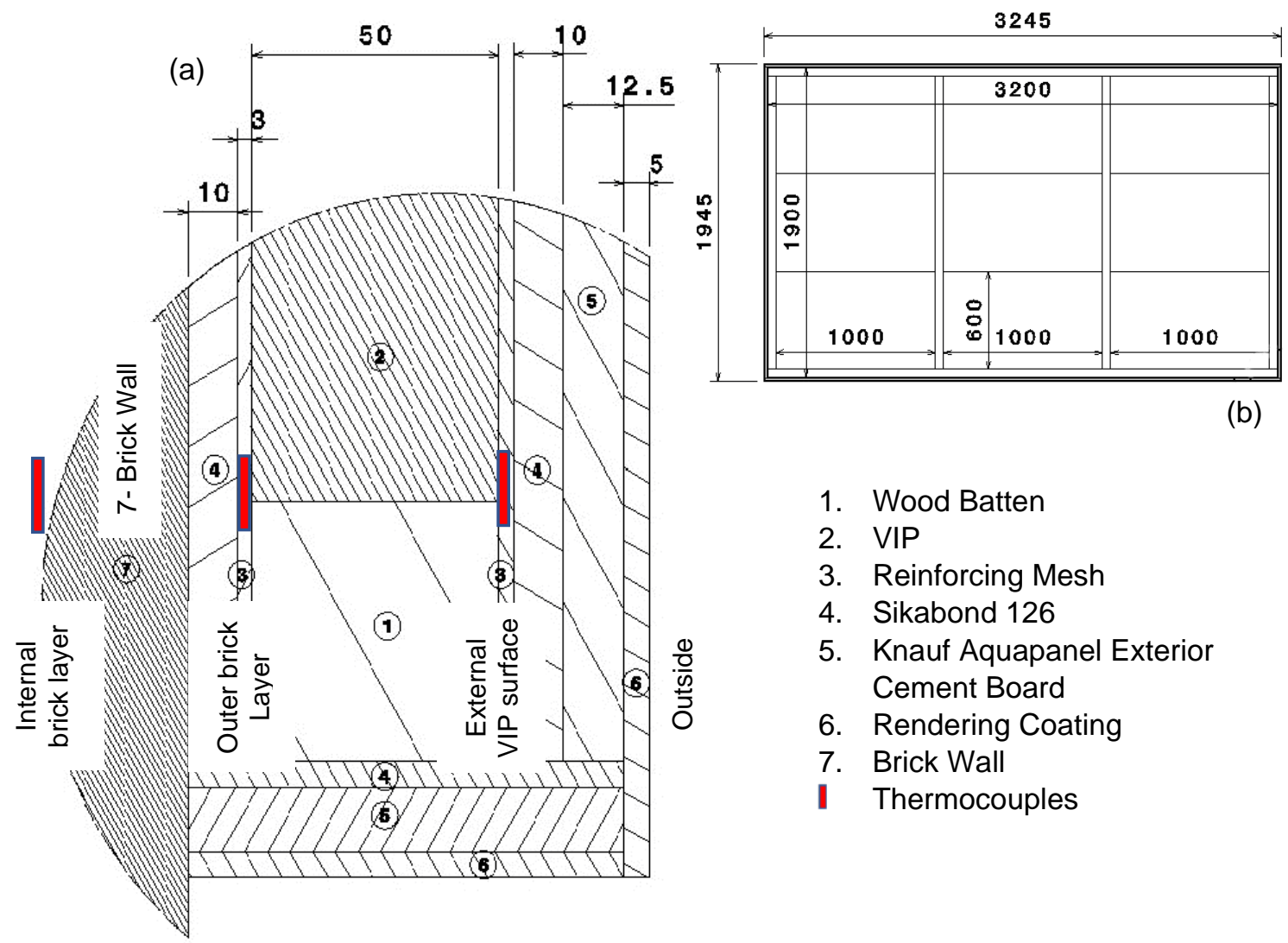

(b)

1. Wood Batten

2. VIP

3. Reinforcing Mesh

4. Sikabond 126

5. Knauf Aquapanel Exterior Cement Board

6. Rendering Coating

7. Brick Wall

I Thermocouples

Fig 5. - (a) Side view- assembly components, (b) Assembly dimensions in mm 


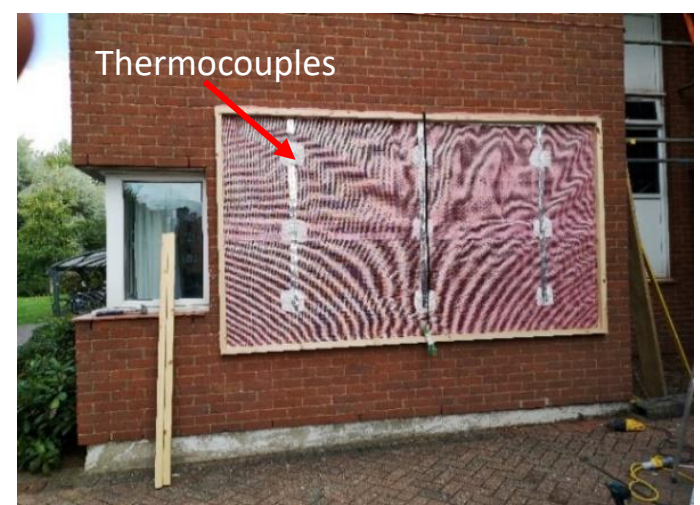

(a) Frame and inner mesh with thermocouples

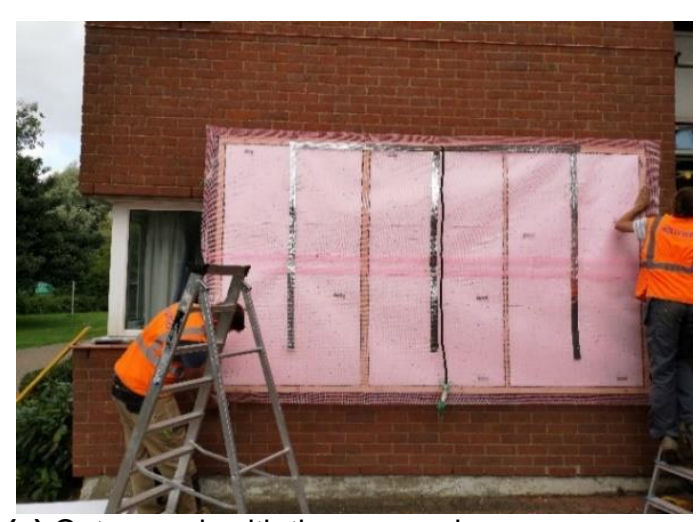

(c) Outer mesh with thermocouples

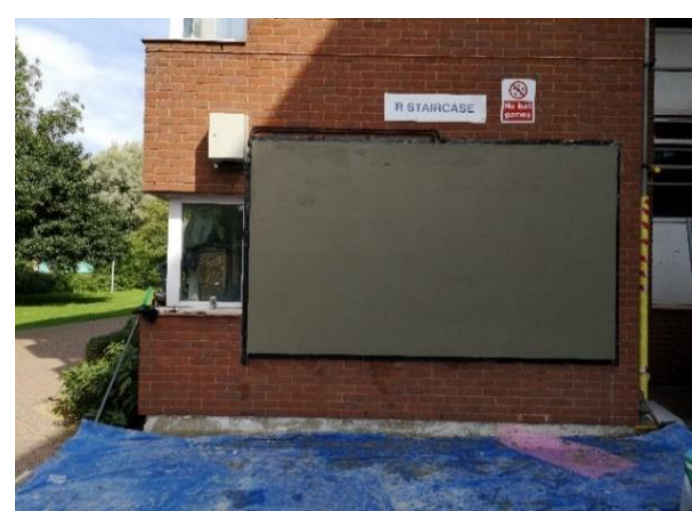

(e) External rendering

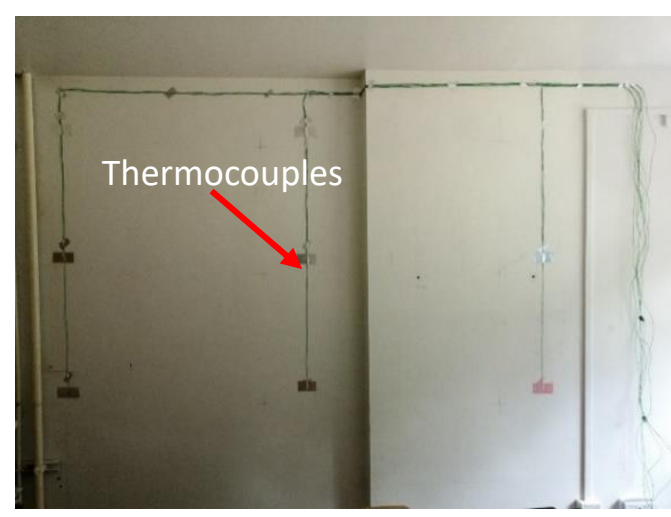

(g) Layout of thermocouples on internal wall surface

Figs. $6 \mathrm{a}$ to $6 \mathrm{~h}-$ Construction procedure

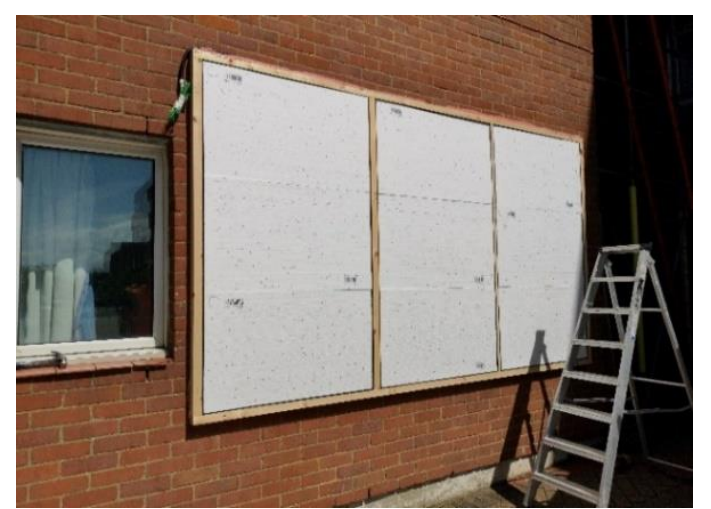

(b) VIPs with EPS covering

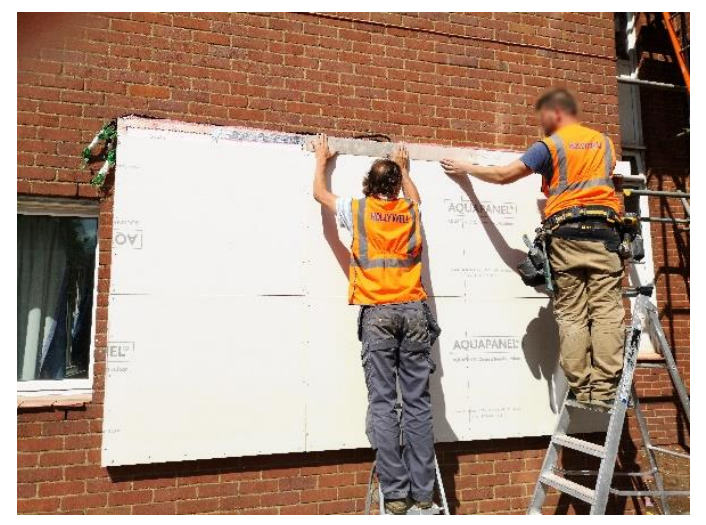

(d) Aquapanel cement board for exterior use

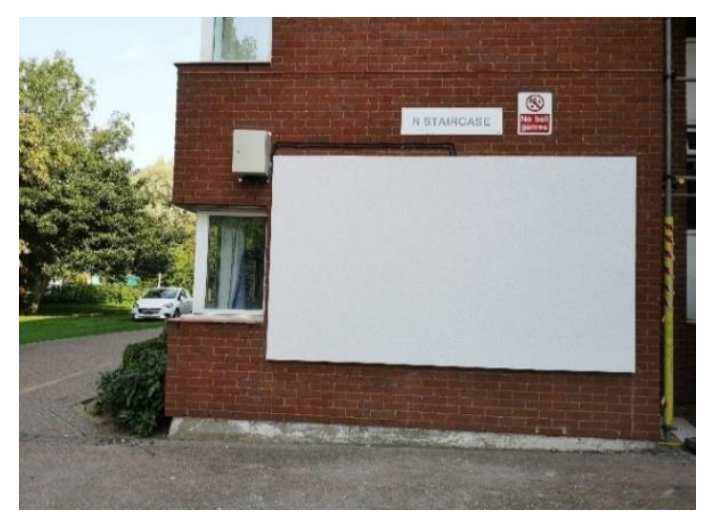

(f) Final external outcome after painting

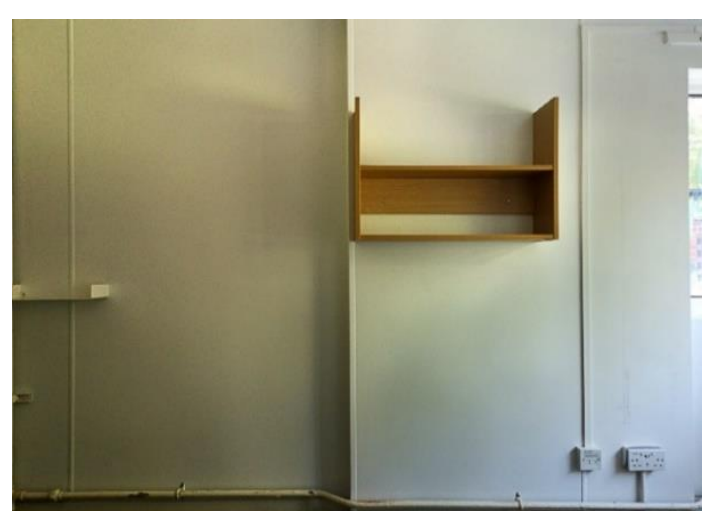

(h) Final interior outcome with Altro White Rock 
The foremost challenge for installation was the lack of accredited installers of VIPs in the UK. As a result, the project team developed a set of installation instructions which were implemented by a team of general builders who were constantly supervised by the project team. It has been ensured that the installation complies with UK's building regulations.

Some adaptations were made during the assembly, namely the introduction of self-adhesive neoprene strips $50 \mathrm{~mm}$ wide to protect the sides of the VIP panels against the wooden battens, which were not protected with EPS as shown on Fig. 3a. This simplified the handling process and consequently there was no damage to any of the VIP panels.

The second adaptation refers to the Sikabond 126 glue. The initial plan was to apply an overall layer of glue on top of all area of the VIP panels. Instead, only a smaller circular area of glue was applied at the centre and both sides of each panel which was found to be sufficient to hold the panels in place. This reduced the overall weight of the system, reduced the working time and costs without affecting the insulation capabilities of the system.

Additionally, no extra steps were applied to the gap bridges between the panels, aiming to assess the efficiency of the VIPs as a product ready for installation directly from the manufacturer without further adaptations. The resultant outcome was very positive as described in the results section.

\section{OPERATIONAL DATA AND RESULTS}

Thermocouples were installed at (i) internal wall surface, (ii) at external wall surface and (iii) at the outmost surface of VIPs to monitor their performance, as shown in the diagram Fig.5a. On the external surfaces a total of 16 thermocouples (Fig. 6a and c) were employed at the centre of each VIP. On the internal layout, 8 thermocouples were positioned parallel to the external layout (Fig $6 \mathrm{~g}$ ). The thermocouples were connected to 12 data loggers of 4 channels each which have been recording temperatures at 10-minute intervals since August 2019 and for the sake of economy of space only January data is shown here. The temperature difference in the two sections (VIPs and brick) is presented in Fig.9 and 10 and in more detail, the temperature difference on individual VIP panels is shown in Figs 11 and 12.

\section{North Wall - Daily Average Temperature}

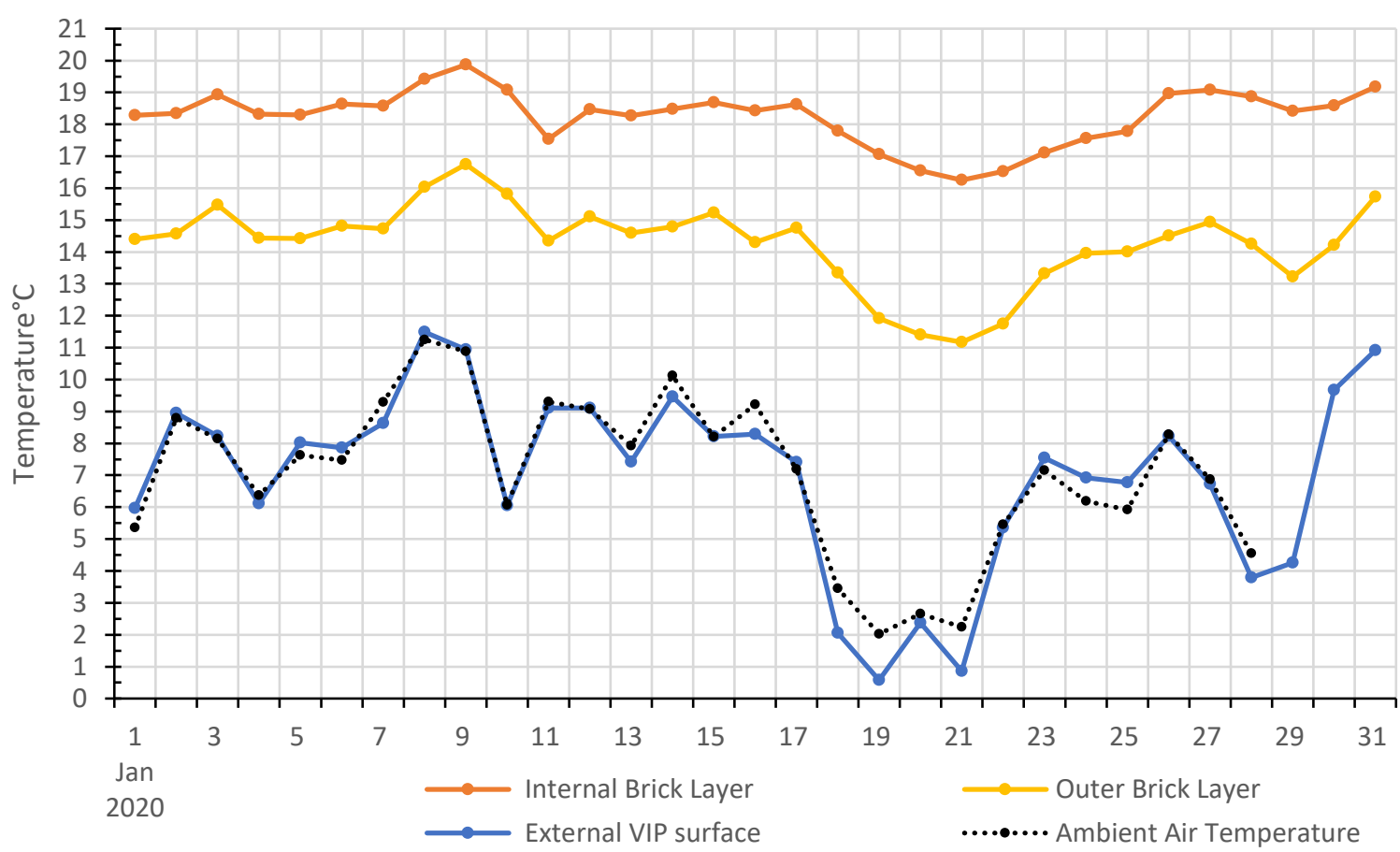

Fig. 7 Daily average temperature at three locations on the VIP north wall 


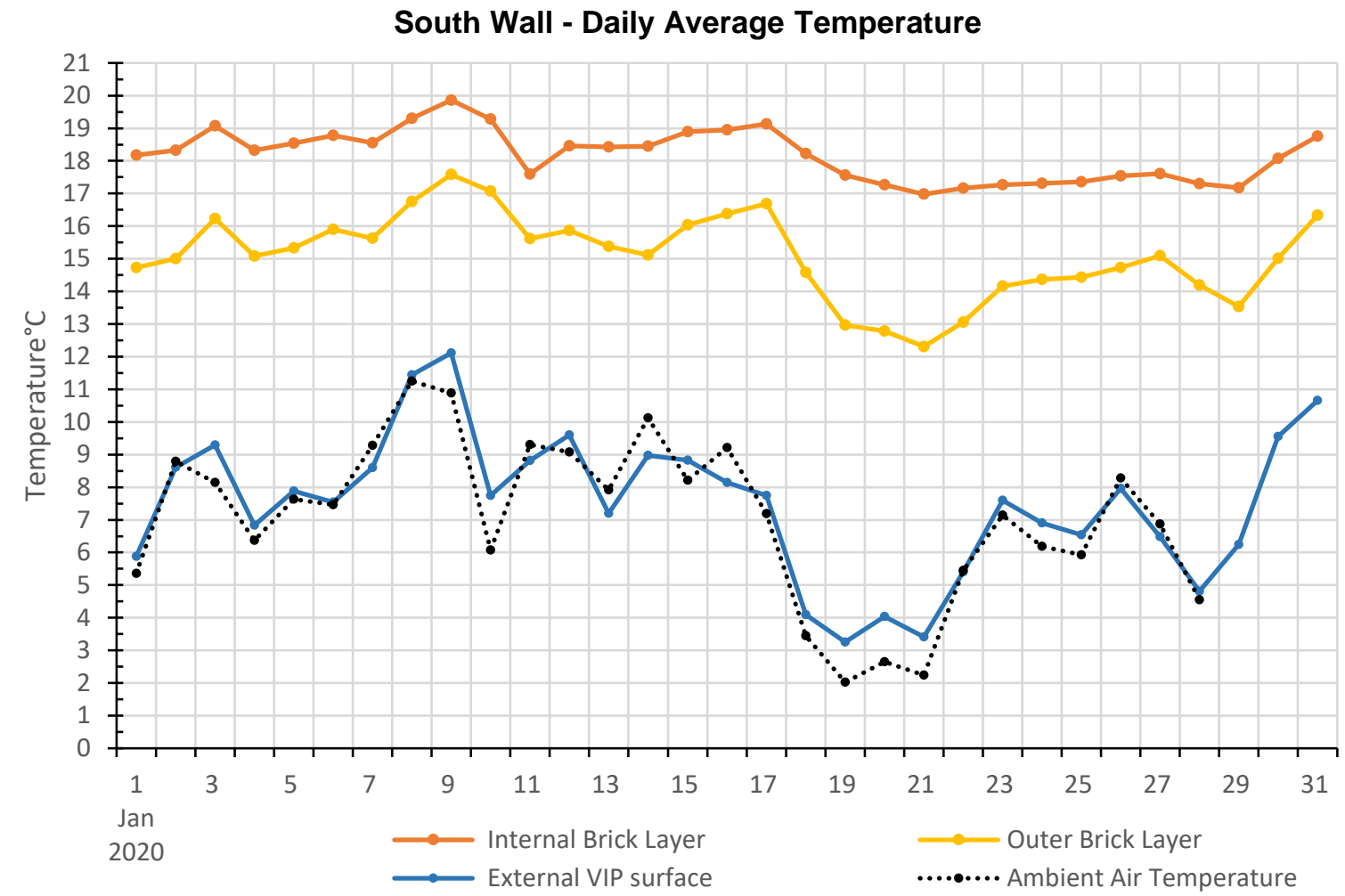

Fig. 8 Daily average temperature at three locations on the VIP south wall

Figs. 7 and 8 show that the measured surface temperatures of the different layers have followed a similar pattern to the ambient air temperature as expected. It can also be seen that the external VIP surface resulted in slightly higher temperature on the south wall as a result of solar radiation. Both walls have returned similar temperature profiles because the rooms were kept at similar temperatures and the ambient conditions were also similar.

\section{North Wall - Difference between measured temperature}

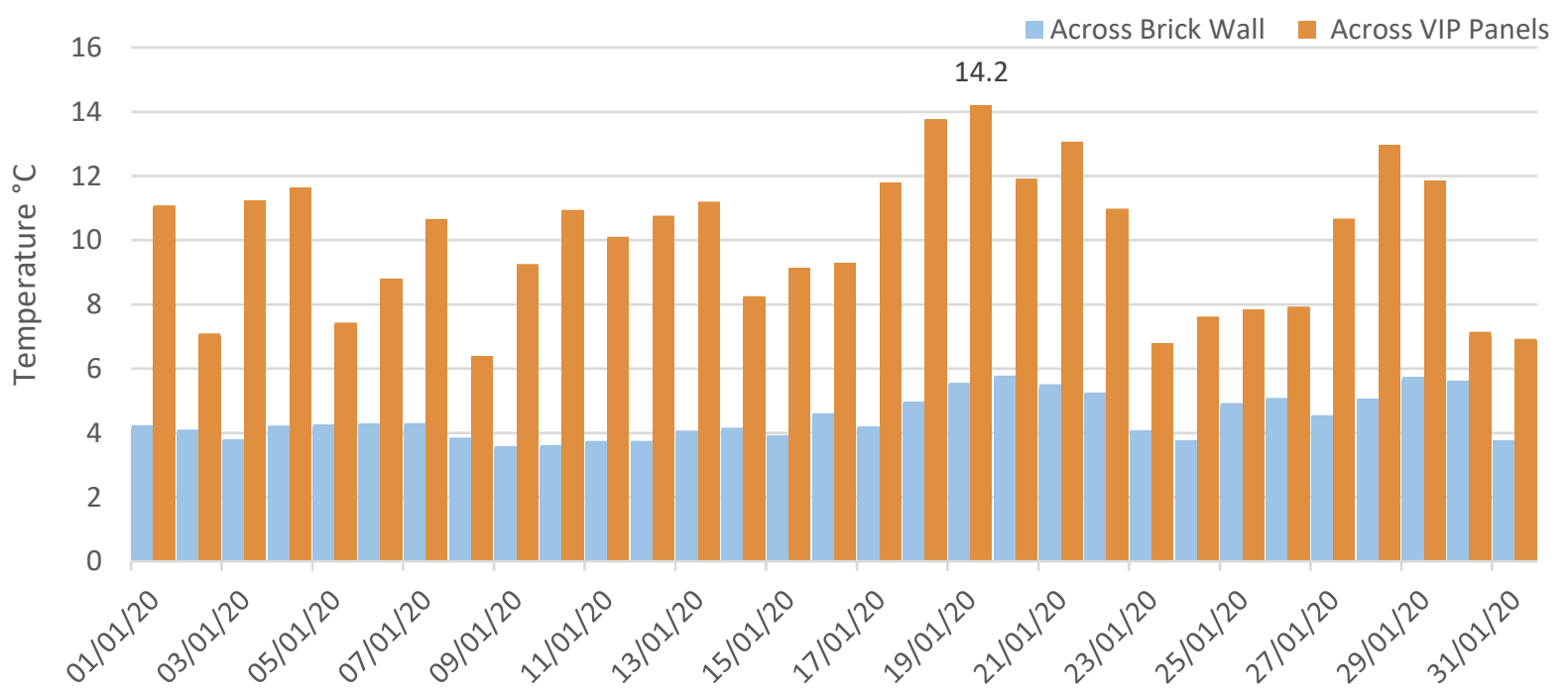

Fig. 9 - North wall - Daily average temperature difference measured across double brick wall (blue) and across VIP centre panel (orange) 


\section{South Wall - Difference between measured temperature}

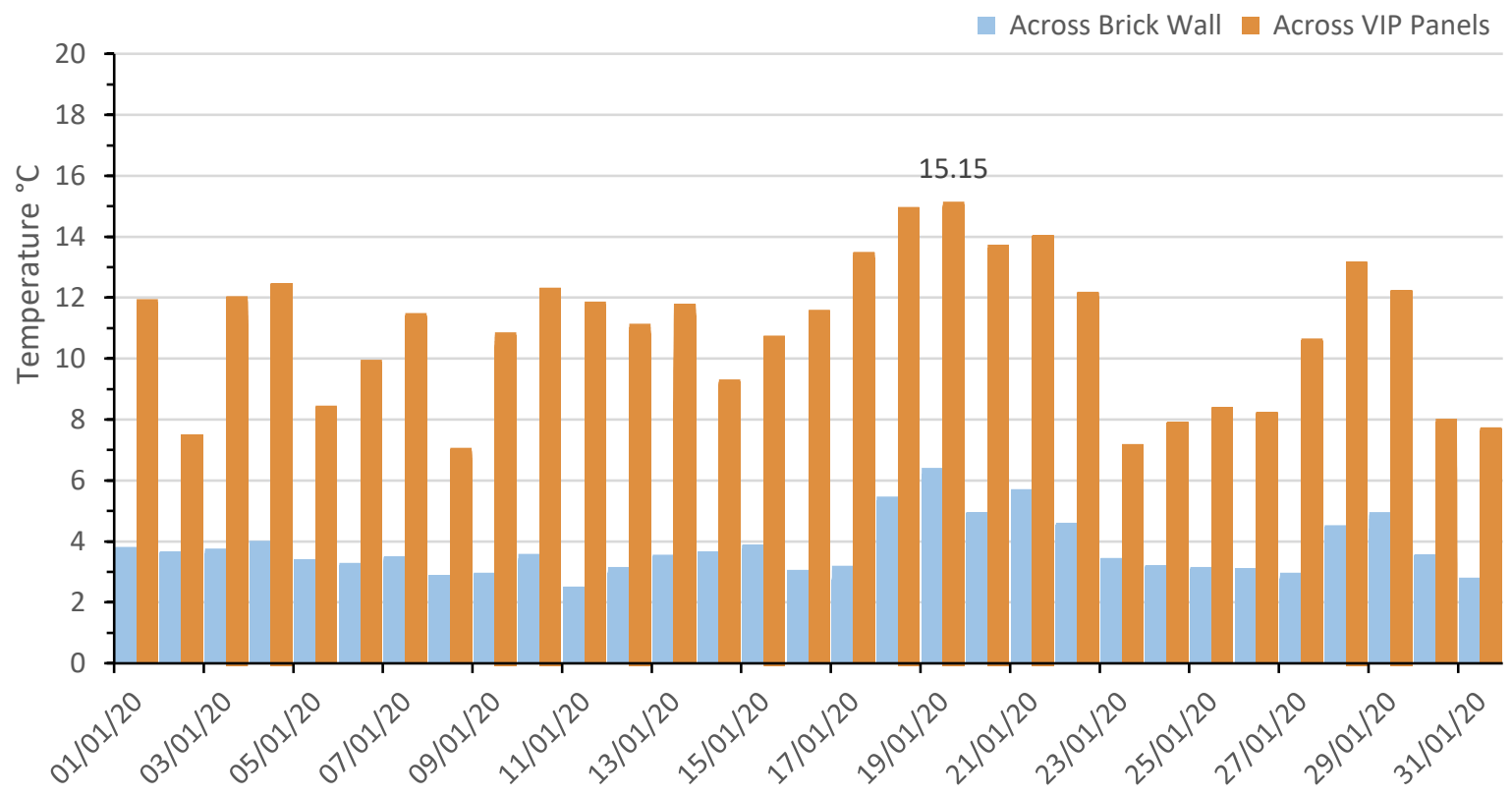

Fig. 10 - South wall - Daily average temperature difference measured across double brick wall (blue) and across VIP centre panel (orange)

Figs 9 and 10 show that the introduction of VIPs on the walls created a maximum temperature difference of $14.2{ }^{\circ} \mathrm{C}$ between the external surface of the north wall and the ambient, and $15.15^{\circ} \mathrm{C}$ on the south wall implying a substantial amount of equivalent heating energy saving. Without the VIPs this energy would be wasted in raising the temperature of the outer brick layer hence reducing thermal comfort for the building occupants, or additional energy would have been used to keep similar levels of thermal comfort.

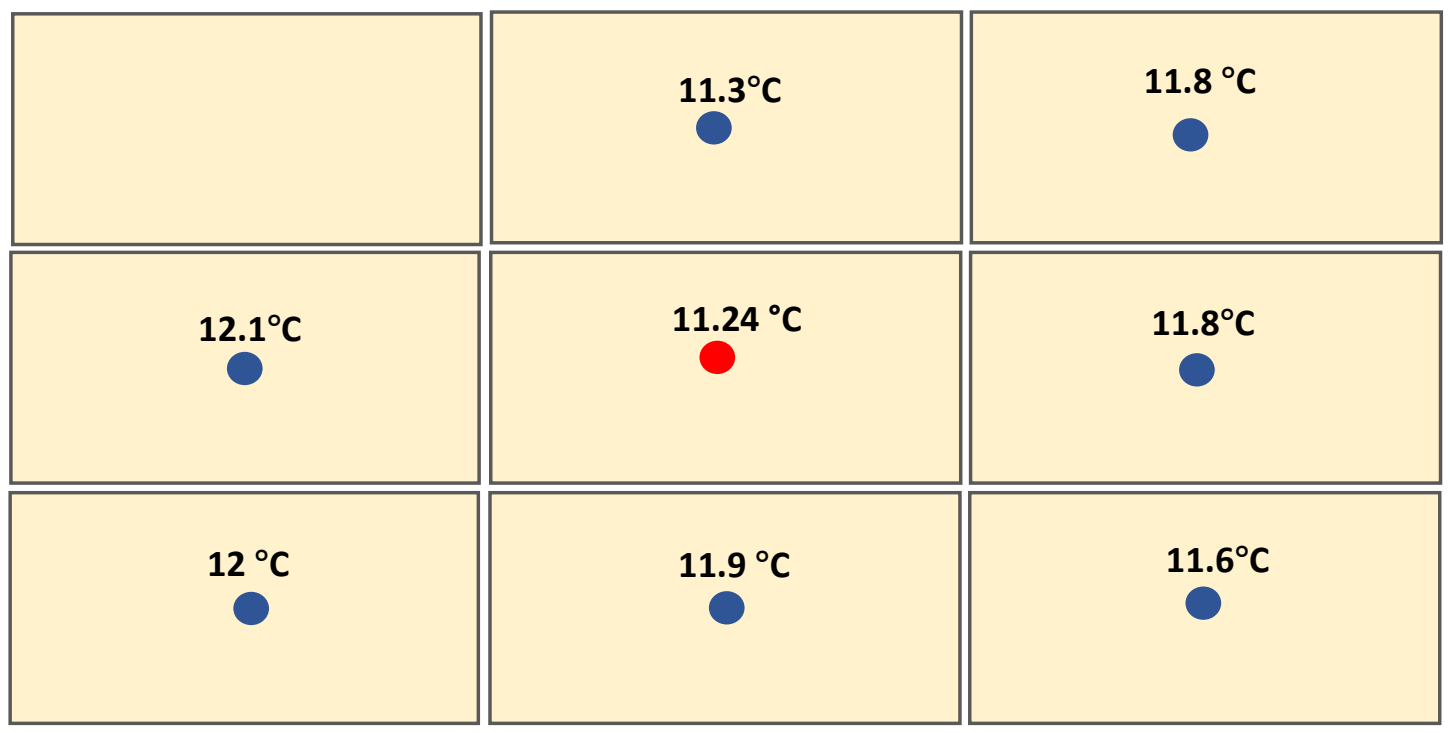

Fig. 11 - North wall - January average temperature difference between internal wall surface and external VIP surface

Fig. 11 shows that the VIPs performed consistently across the whole installation providing a stable temperature distribution to the wall. It is evident by the recorded temperatures that the installation method developed has significantly reduced thermal bridging effect between any two adjacent VIPs. A slight increase in temperature can be observed on the panels at the edge of the installation which 
reflects the effect of heat lost as a consequence of the uninsulated sections of the wall relative the central panel which is surrounded by other VIPs. Similar temperature profiles were measured for the South wall are shown in Fig. 12.

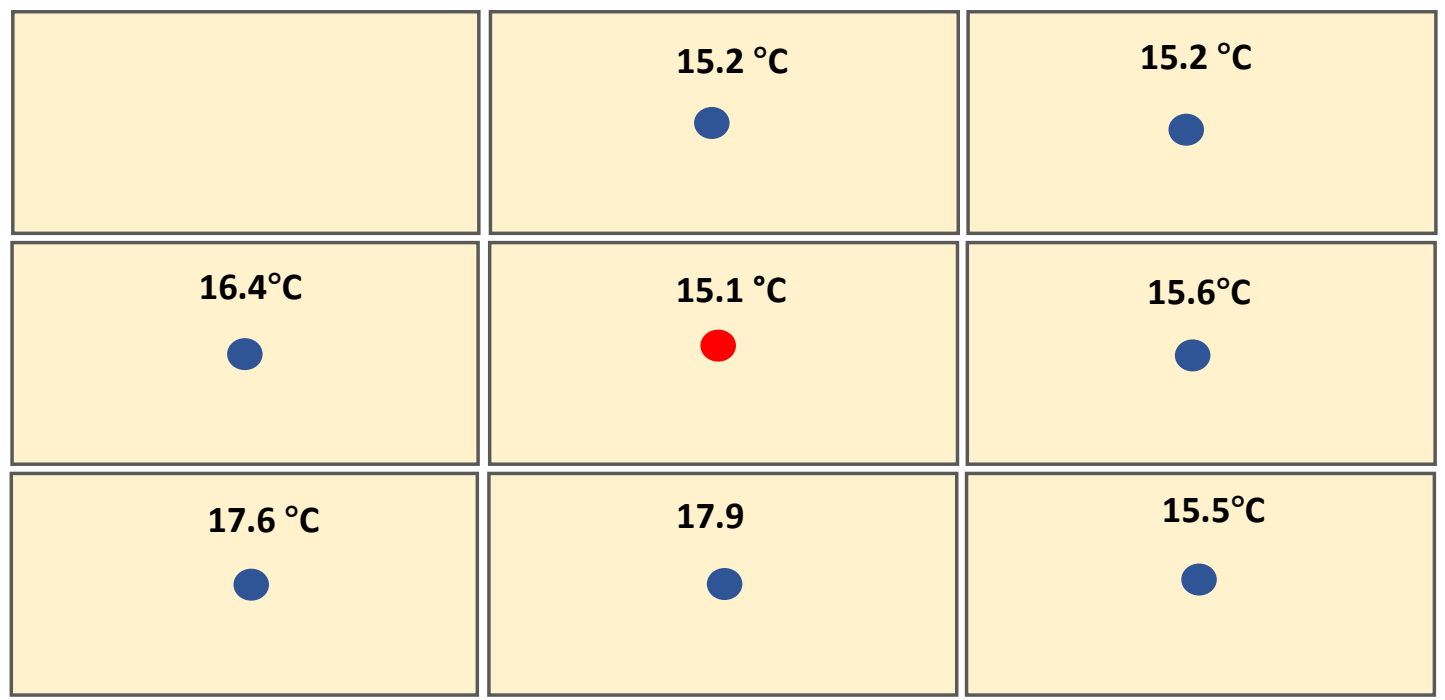

Fig. 12 - South wall - January average temperature on external wall surface

Fig.12 shows the average temperature for the external wall surface on the south wall installation as opposed to the temperature difference across all installation shown in Fig. 11. It can be seen that the temperatures recorded follow a similar pattern of higher temperatures on the VIPs at the edges of the installation relative to the central VIP. This can be as a result of the uninsulated areas of the wall, nonetheless, it is worth noticing that the south wall is partially exposed to direct sunlight for most of the day which implies the effect of solar radiation might account for the higher difference in temperature from the centre VIP as shown on Fig. 14. The January average temperature was $18.1^{\circ} \mathrm{C}$ and $7.1^{\circ} \mathrm{C}$ on the inside wall surface and on the external VIP surface respectively. With an average temperature of $15.1^{\circ} \mathrm{C}$ at the central panel, the VIP installation proved to be an efficient barrier against heat loss.

On Fig. 13 shows that the chosen installation method helped to reduce the effect of heat bridges which has been a major concern for building scientists and developers because these can lead to a complete loss of value that could be gained from VIP installations. Fig.14 shows the effect of solar radiation on the partially shaded installation on the south wall.

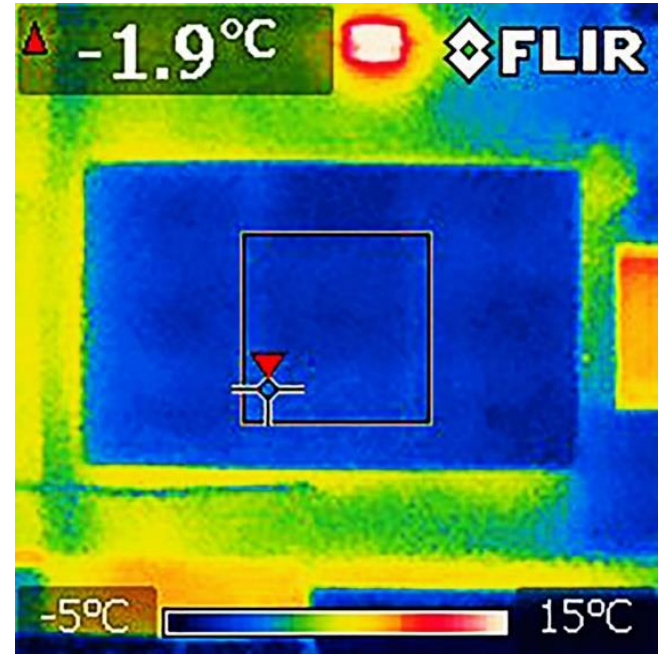

Fig. 13 - Thermal Image - North Wall

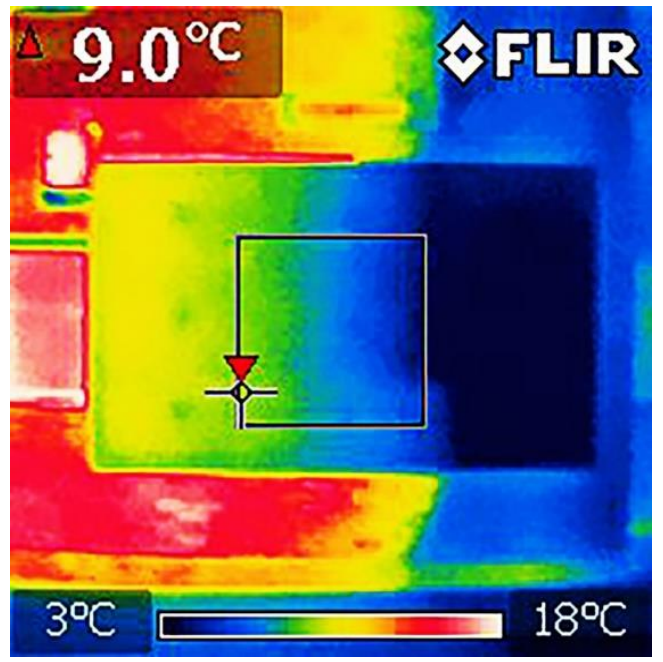

Fig. 14 - Thermal Image - South Wall 


\section{CONCLUSIONS}

The installation method developed for the $\mathrm{ReCO}_{2} \mathrm{ST}$ project has significantly reduced thermal bridging effect between any two adjacent VIPs hence reducing heat loss and thus improving the installation performance in the long term. Many installation challenges associated with the handling of the VIPs at the installation phase such as punctures were overcome through appropriate construction design methods. The choice of VIPs with EPS sheet covering provided by the $\mathrm{ReCO}_{2} \mathrm{ST}$ partner va-Q-tec also reduced the vulnerability of the VIPs while reducing the risk of surface condensation.

VIPs have been found to reduce heat transfer from the ambient with a fraction of the thickness compared to typically used insulation materials, leading to a significant reduction in the amount of heat energy required to maintain indoor thermal comfort conditions. Work continues to quantify the potential energy savings for this demonstration building.

\section{ACKNOWLEDGMENTS}

This project has received funding from the European Union's Horizon 2020 Research and Innovation program under Grant Agreement No 768576

\section{REFERENCES}

1. Brunner $\mathrm{S}$, Simmler $\mathrm{H}$. In situ performance assessment of vacuum insulation panels in a flat roof construction. Vacuum 2008;82:700-7.

2. K. Ghazi-Wakili, R. Bundi, B. Binder, Effective thermal conductivity of vacuum insulation panels, Building Research \& Information 32 (4) (2004) 293-299.

3. European Commission, EU Energy and Transport in Figures - Statistical Pocketbook 2010, European Union, Luxemburg, 2010, ISBN 978-92-79-13815-7

4. P. Karami, Robust and Durable Vacuum Insulation Technology for Buildings Doctoral thesis in Building Tecknology, KTH University, Stockholm, Sweden, 2015

5. A. Lorenzati, S. Fantucci, A. Capozzoli, M. Perino, Experimental and numerical investigation of thermal bridging effects of jointed Vacuum Insulation Panels, Energy Build. 111 (2016) 164-175, doi:10.1016/j.enbuild.2015.11.026.

6. F. Isaia, S. Fantucci, A. Capozzoli, M. Perino, Thermal bridges in vacuum insulation panels at building scale, Eng. Sustainability (2016) $1-14$. doi.org/10.1680/ jensu.15.00057.

7. M. Alam, H. Singh S. Suresh and D.A.G. Redpath, 2017, Economic analysis of Vacuum Insulation Panels (VIPs) used in non-domestic buildings, Applied Energy 188, 1-8.

8. N. Shukla, A. Fallahi, J. Kosny', (2013). VIP - technology review and cost study for building retrofits in Northern US locations, in: Thermal Performance of the Exterior Envelopes of Whole Buildings XII International Conference, ASHRAE, 2013, pp. 1-9

9. ReCO2ST - https://reco2st.eu/ 